\title{
Revisión bibliográfica exploratoria sobre los criterios de aptitud en conductores profesionales con enfermedad psiquiátrica
}

\section{Literature review on the fitness criteria of professional drivers with mental disorders}

\author{
Carlos Álava Urrburu ', Inés Huerta Rodríguez ${ }^{2}$, Marian Noval Vallina 3 ,4 \\ 1. Unidad Docente de Euzkadi. Hospital Basurto. Bilbao (Vizcaya). España. \\ 2. Unidad Docente de Asturias. Hospital Universitario Central Asturias. Oviedo (Asturias). España. \\ 3. Unidad Docente de Asturias. Hospital Cabueñes. Giión (Asturias). España. \\ 4. Unidad Docente de Castilla La Mancha. Fremap. Toledo. España.
}

Recibido: 30-01-11

Aceptado: 16-02-11

\section{Correspondencia}

Carlos Alava Urraburu

Hospital de Basurto. Servicio de Salud Laboral

Avd. Montevideo n 18

48013 Bilbao (Vizcaya). España

Tlfn: 647417798

E-mail: calava@yahoo.com

Resumen

Criterios de aptitud en conductores con patología mental

Introducción: La OMS estima que los accidentes de tráfico y las enfermedades mentales serán los principales problemas de salud en el primer tercio del S. XXI. El RD 818/2009 (Reglamento General de Conductores (BOE)) dispone que es indispensable para la obtención de los permisos y licencias de conducción reunir unos determinados requisitos de aptitud psicofísica. Las pruebas psicotécnicas homologadas en España son: ASDE Driver Test N-845, L.N.DETER 100 y Coordinator 2000.

Objetivos: Conocer el efecto en la capacidad de conducción de las personas con patología mental y la normativa de aplicación en la valoración de la aptitud de los conductores profesionales.

Metodología: Se realizó una búsqueda en diferentes bases de datos y bibliotecas y de una recopilación de 909 artículos, se seleccionaron para lectura a texto completo 17. Se clasificaron por grupos de enfermedades mentales según el modelo del RD 818/2009 del Reglamento General de Conductores, que las clasifica en 11 grupos de los que analizamos 8 , por considerarlos de más relevancia.

Resultados: El RD818/2009, regula de manera estricta la aptitud o no en enfermos mentales. Aproximadamente el $80 \%$ de los pacientes con enfermedades mentales no pasa los test psico-técnicos, a no ser que sean patologías leves con poca sintomatología, y el paciente tenga un informe favorable del psiquiatra o psicólogo.

Conclusiones: El Reglamento General de Conductores dispone que las limitaciones para conducir sean acreditadas por un especialista. No se encuentra suficiente evidencia sobre si los test psico-técnicos utilizados en las pruebas de aptitud psicofísicas son suficientemente sensibles y específicos para la detección de trastornos mentales. Existe el deber moral del paciente de informar al médico, si su patología pone en peligro la seguridad vial, pero no la obligación legal.

Med Segur Trab (Internet) 2011; 57 (222) 41-62

Palabras clave: Trastornos mentales. Conducción de automóviles. Accidentes de tráfico. Aptitud. 
Abstract

Introduction: WHO estimates that traffic accidents and mental disorders will be the main health problems in the first third of the XXI Century. The Spanish Law for drivers (RD 818/2009 Reglamento General de Conductores) mentions the necessity of meeting certain psychophysical requirements to obtain a driving license. Psychological tests approved in Spain are: ASDE Driver Test N-845, 100 and Coordinator LNDETER 2000.

Objectives: Investigate the driving ability of people with mental disorders and know the legal aspects of professional drivers' fitness assessment.

Methods: We conducted a research in different databases, libraries and out of a collection of 909 articles, 17 of them were selected for full revision. Mental disorders were classified according to Spanish regulation for drivers into 11 groups. We selected 8, because we considered them to be the most relevant.

Results: RD 818/2009 strictly regulates the fitness for work of patients with mental disorders. Around $80 \%$ of patients with mental disorders do not pass the fitness tests, unless they have few symptoms, or those patients who have a favourable psychiatrist or psychologist report.

Conclusions: The Spanish Law for drivers mentions that driving limitations must be accredited by a specialized physician. There is not enough evidence of the sensitivity and specificity of psycho-technical tests used in detecting mental disorders. The patient has a moral duty to inform his doctor about his pathology if it implies danger for others, but there is not a legal obligation.

Med Segur Trab (Internet) 2011; 57 (222) 41-62

Key words: Mental disorders, Automobile Driving. Traffic accidents. Aptitude. 


\section{INTRODUCCIÓN}

La Organización Mundial de la Salud (OMS) estima que los accidentes de tráfico y las enfermedades mentales serán los principales problemas de salud en el primer tercio del S. XXI. El 23,73\% de la población sufrirá un trastorno mental a lo largo de su vida y la mayoría de estos recibirán un tratamiento farmacológico. En España los accidentes de circulación suponen la primera causa de mortalidad hasta los 35 años (en hombres hasta los 45 años). El Manual de medidas de seguridad vial de Rune Elvik y Truls Vaa refiere que el riesgo de los accidentes de tráfico en enfermos mentales es 1.45 veces mayor que en los sanos ${ }^{1}$.

El Real Decreto (RD) 818/2009, de 8 de Mayo por el que se regula el Reglamento General de Conductores ${ }^{2}$ dispone que es indispensable para la obtención de los permisos y licencias de conducción reunir unos requisitos de aptitud psicofísica, habilidades, aptitudes, comportamientos y conocimientos. Las pruebas de aptitud psicofísica van encaminadas a dejar constancia de que no debe haber enfermedad o deficiencia asociada que suponga incapacidad para conducir. Así pues, el RD establece los criterios de aptitud para la conducción de vehículos a motor ${ }^{i}$ en conductores no profesionales (grupo 1) y conductores profesionales ${ }^{\text {ii }}$ (grupo 2) cuando presentan enfermedades orgánicas $o$ enfermedades mentales (sobre las que versa la presente revisión bibliográfica) (Ver Tabla 2) que puedan mermar la capacidad para conducir. Las aptitudes exigidas en el ejercicio de la conducción serán reevaluadas periódicamente por los servicios sanitarios competentes. Las pruebas psicotécnicas homologadas en España, y que se utilizan de forma estándar para la obtención y renovación del carné de conducir, son las pruebas ASDE (Driver Test N-845), L.N.DETER 100 y Coordinator 2000³. Puede haber suspensión cautelar de la vigencia del permiso o de la licencia de conducción cuando su mantenimiento en vigor entrañe un grave peligro para la seguridad vial.

El RD 1032/2007, de 20 de Julio, regula la cualificación inicial y la formación continua de los trabajadores del transporte por carretera.

En el ámbito de la empresa, En España, en torno al 40\% de los accidentes laborales mortales tienen lugar en la carretera, siendo el 70\% de ellos conductores no profesionales cuando acuden a sus trabajos o cuando retornan de ellos, es decir, accidentes "in itinere" ${ }^{1}$ Se considerará accidente de trabajo a todo accidente de tráfico que cumpla las premisas expuestas en el RD 1/1994 (Art. 115) de la Ley General de la Seguridad Social. (Ver anexo I). Los accidentes de trabajo relacionados con tráfico han ido en aumento.

Los planes de prevención de las empresas suelen acotarse a los centros de trabajo dejando de lado el ámbito de la seguridad vial. Teniendo en cuenta que 4 de cada 10 accidentes de trabajo mortales están relacionados con el tráfico, siendo dos de cada tres "in itinere" ${ }^{1}$ está claro que a la Medicina del Trabajo le queda una ardua tarea por realizar en este campo.

Una correcta Vigilancia de la Salud debiera registrar en la historia clinico-laboral los hábitos de conducción y los cambios en las condiciones psicofísicas que comprometen la aptitud del trabajador para conducir. Una de las funciones principales del médico del trabajo es establecer los criterios de aptitud para la conducción de una manera lo más individualizada posible que englobe las aptitudes médicas y psicológicas mínimas razonables para una conducción segura. También forma parte de su función educar al conductor con problemas de salud crónicos o agudos en las precauciones que debe tomar y en las estrategias de prevención que ha de poner en marcha. Pero en la práctica ésta es una ardua tarea que no se realiza bajo estas premisas.

\footnotetext{
i Se define "vehículo a motor" (2): Vehículo provisto de motor para su propulsión (se excluyen de esta definición los ciclomotores, los tranvías y los vehículos para personas de movilidad reducida)

ii Se define como "conductor profesional", a efectos de lo dispuesto en la Ley 17/2005, de 19 de julio , "toda persona provista de la correspondiente autorización administrativa para conducir, cuya actividad laboral principal sea la conducción de vehículos a motor dedicados al transporte de mercancías o de personas, extremo que se acreditará mediante certificación expedida por la empresa para la que ejerza aquella actividad, acompañada de la correspondiente documentación acreditativa de la cotización a la Seguridad Social como trabajador de dicha empresa".
} 
Con todo ello y bajo el marco legislativo que establece el RD 818/2009 competerá a los centros homologados para la expedición y renovación de la licencia de conducción, con el apoyo de los especialistas pertinentes, la identificación en los exámenes de salud de aquellos trastornos mentales que puedan disminuir la aptitud psicofísica y, por tanto, afectar negativamente a la capacidad para conducir en aquellos puestos de trabajo que requieran de esta actividad (conductores profesionales) proponiendo adaptaciones en los casos en los que sea posible, o bien informando a las autoridades legales para que éstas actúen en consecuencia.

\section{OBJETIVOS}

1. Conocer qué efectos producen en la capacidad de conducción las patologías mentales.

2. Revisar la normativa de aplicación en la valoración de la aptitud de los conductores profesionales.

3. Establecer el papel del médico del trabajo en la valoración de la de aptitud para la conducción de conductores profesionales con patología mental.

\section{METODOLOGÍA}

Se han utilizado para la búsqueda de publicaciones las bases de datos en línea Pubmed, Índice Bibliográfico Español en Ciencias de la Salud (IBECS), Índice Bibliográfico de Salud y Seguridad en el Trabajo (IBSST), Occupational Safety and Health (OSHUPDATE), Web of Knowledge (WOK), ScIELO España y Biblioteca Cochrane Plus.

El enfoque inicial de la búsqueda se orientó hacia la obtención de publicaciones sobre la población objetivo, es decir, hacia conductores profesionales con patología psiquiátrica y los criterios de aptitud para la conducción. Ante la dificultad de encontrar literatura escrita la búsqueda se reorientó especificando los grupos de trastornos mentales a los que hace referencia el RD 818/2009 y su vinculación respecto a la aptitud para el ejercicio de la conducción obteniendo, de esta manera, unos resultados de búsqueda más dirigidos y específicos de población general que serán extrapolables a los conductores profesionales. La estrategia de búsqueda realizada queda reflejada en la Tabla 1.

Tabla 1. Estrategia de búsqueda bibliográfica.

\begin{tabular}{|c|c|c|c|}
\hline BASES DE DATOS & DESCRIPTORES & LÍMITES & $\begin{array}{c}\text { ARTÍCULOS } \\
\text { ENCONTRADOS }\end{array}$ \\
\hline OSH UPDATE & (Automobile driver) & Sin límites & 71 \\
\hline OSH UPDATE & (Drivers) AND (Depressive neurosis) & Sin límites & 5 \\
\hline OSH UPDATE & $\begin{array}{l}\text { (Atomobile driver) AND (Psychiatry) OR } \\
\text { (Mental health) OR (Mental disorders) }\end{array}$ & Sin límites & 0 \\
\hline WOK & (Mental health) AND (Drivers) & Sin límites & 68 \\
\hline WOK & $\begin{array}{l}\text { (Mental disorders) AND } \\
\text { (Managemment) AND } \\
\text { (Professional drivers) }\end{array}$ & Sin límites & 0 \\
\hline WOK & $\begin{array}{l}\text { (Mental health) AND (driving) } \\
\text { AND (manpower) }\end{array}$ & Sin límites & 0 \\
\hline WOK & $\begin{array}{l}\text { (Mental Health) AND } \\
\text { (Professional Drivers) }\end{array}$ & Sin límites & 0 \\
\hline IBECS & $\begin{array}{l}\text { (Salud Mental) Y (Examen de Aptitud para la } \\
\text { Conducción de Vehículos) }\end{array}$ & Sin límites & 1 \\
\hline IBSST & (Accidente de circulación) & Sin límites & 30 \\
\hline
\end{tabular}




\begin{tabular}{|c|c|c|c|}
\hline BASES DE DATOS & DESCRIPTORES & LÍMITES & $\begin{array}{c}\text { ARTÍCULOS } \\
\text { ENCONTRADOS }\end{array}$ \\
\hline IBSST & (Salud Mental) Y (Accidentes de circulacción) & Sin límites & 1 \\
\hline PUBMED & "mental disorders" AND "driver" & All Adult: $19+$ years & 76 \\
\hline PUBMED & $\begin{array}{l}\text { "Automobile Driving/standards"[Mesh] AND } \\
\text { "Mental Disorders"[Mesh]" }\end{array}$ & $\begin{array}{l}\text { Published in the last } 5 \text { years, } \\
\text { All Adult: } 19+\text { years }\end{array}$ & 26 \\
\hline PUBMED & $\begin{array}{l}\text { "automobile driving"[Mesh] AND "mental } \\
\text { disorders"[Mesh] }\end{array}$ & $\begin{array}{l}\text { Humans, Clinical Trial, All } \\
\text { Adult: } 19+\text { years }\end{array}$ & 28 \\
\hline PUBMED & $\begin{array}{l}\text { "Accidents, Traffic"[Majr] AND "Delirium, } \\
\text { Dementia, Amnestic, Cognitive Disorders"[Majr] }\end{array}$ & $\begin{array}{l}\text { Young Adult: } 19-24 \text { years } \\
\text { Adult: } 19-44 \text { years } \\
\text { Middle Aged: } 45-64 \text { years }\end{array}$ & 30 \\
\hline PUBMED & $\begin{array}{l}\text { "Automobile Driving"[Majr] AND "Delirium, } \\
\text { Dementia, Amnestic, Cognitive Disorders"[Majr }\end{array}$ & $\begin{array}{l}\text { Young Adult: } 19-24 \text { years } \\
\text { Adult: } 19-44 \text { years } \\
\text { Middle Aged: } 45-64 \text { years }\end{array}$ & 98 \\
\hline PUBMED & $\begin{array}{l}\text { "Automobile Driving"[Majr] AND "Mood } \\
\text { Disorders"[Majr] }\end{array}$ & $\begin{array}{l}\text { Young Adult: } 19-24 \text { years } \\
\text { Adult: } 19-44 \text { years } \\
\text { Middle Aged: } 45-64 \text { years }\end{array}$ & 14 \\
\hline PUBMED & $\begin{array}{l}\text { "Mood Disorders"[Majr] AND "Accidents, } \\
\text { Traffic"[Majr] }\end{array}$ & $\begin{array}{l}\text { Young Adult: } 19-24 \text { years } \\
\text { Adult: } 19-44 \text { years } \\
\text { Middle Aged: } 45-64 \text { years }\end{array}$ & 13 \\
\hline PUBMED & $\begin{array}{l}\text { ((("Mood Disorders"[Majr]) AND "Automobile } \\
\text { Driving"[Majr]) AND "manpower "[Subheading] }\end{array}$ & $\begin{array}{l}\text { Young Adult: } 19-24 \text { years } \\
\text { Adult: } 19-44 \text { years } \\
\text { Middle Aged: } 45-64 \text { years }\end{array}$ & 0 \\
\hline PUBMED & $\begin{array}{l}\text { (("Personality Disorders"[Mesh] OR "Passive- } \\
\text { Aggressive Personality Disorder"[Mesh] OR } \\
\text { "Schizotypal Personality Disorder"[Mesh] OR } \\
\text { "Schizoid Personality Disorder"[Mesh] OR } \\
\text { "Paranoid Personality Disorder"[Mesh] OR } \\
\text { "Histrionic Personality Disorder"[Mesh] OR } \\
\text { "Compulsive Personality Disorder"[Mesh] OR } \\
\text { "Antisocial Personality Disorder"[Mesh] OR } \\
\text { "Multiple Personality Disorder"[Mesh] OR } \\
\text { "Borderline Personality Disorder"[Mesh] OR } \\
\text { "Dependent Personality Disorder"[Mesh])) AND } \\
\text { "Automobile Driving”[Mesh] }\end{array}$ & $\begin{array}{l}\text { Young Adult: } 19-24 \text { years } \\
\text { Adult: } 19-44 \text { years } \\
\text { Middle Aged: } 45-64 \text { years }\end{array}$ & 27 \\
\hline PUBMED & $\begin{array}{l}\text { ("Attention Deficit and Disruptive Behavior } \\
\text { Disorders"[Mesh] OR "Attention Deficit } \\
\text { Disorder with Hyperactivity"[Mesh]) AND } \\
\text { "Automobile Driving"[Mesh] AND ("young } \\
\text { adult"[MeSH Terms] OR "adult"[MeSH } \\
\text { Terms:noexp] OR "middle aged"[MeSH Terms]) } \\
\text { Terms:noexp] OR "middle aged"[MeSH Terms]) }\end{array}$ & $\begin{array}{l}\text { Young Adult: } 19-24 \text { years } \\
\text { Adult: } 19-44 \text { years } \\
\text { Middle Aged: } 45-64 \text { years }\end{array}$ & 41 \\
\hline PUBMED & $\begin{array}{l}\text { "Schizophrenia"[Mesh] AND "Accidents, } \\
\text { Traffic"[Mesh]" }\end{array}$ & Sin límites & 19 \\
\hline PUBMED & $\begin{array}{l}\text { "Schizophrenia"[Mesh] AND "manpower } \\
\text { "[Subheading] }\end{array}$ & Sin límites & 56 \\
\hline PUBMED & (dissociative disorder) AND (accidents, Traffic) & All Adult: $19+$ years & 34 \\
\hline PUBMED & (dissociative disorder) AND (manpower) & All Adult: 19+ years & 1 \\
\hline PUBMED & $\begin{array}{l}\text { "Automobile Driving"[Majr] AND "Sleep } \\
\text { Disorders"[Majr] }\end{array}$ & $\begin{array}{l}\text { Young Adult: } 19-24 \text { years } \\
\text { Adult: } 19-44 \text { years Middle } \\
\text { Aged: } 45-64 \text { years }\end{array}$ & 165 \\
\hline PUBMED & $\begin{array}{l}\text { ("Automobile Driving"[Majr] AND “Sleep } \\
\text { Disorders"[Majr]) ) NOT "Sleep Apnea } \\
\text { Syndromes"[Majr] }\end{array}$ & $\begin{array}{l}\text { Young Adult: } 19-24 \text { years } \\
\text { Adult: } 19-44 \text { years Middle } \\
\text { Aged: } 45-64 \text { years }\end{array}$ & 97 \\
\hline PUBMED & $\begin{array}{l}\text { "Mental Retardation"[Mesh] AND "Automobile } \\
\text { Driving"[Majr] }\end{array}$ & Sin límites & 8 \\
\hline
\end{tabular}


La revisión bibliográfica no establece límites en las fechas de las publicaciones, sin embargo sí se define el rango de edad entre mayores de 19 años (a partir de los cuales se puede obtener el carnet de conducir, sin tener en cuenta los años de experiencia que a veces se requiere para algún tipo de carné) y 65 años (edad mínima para acceder a la prestación por jubilación). Aunque se es consciente de que existe una importante población trabajadora autónoma, y que por lo tanto superarían el límite de los 65 años, no se les ha incluido en el estudio por razones logísticas.

De esta manera, los criterios de inclusión serán:

- Conductores profesionales y no profesionales.

- Edad entre 19 y 65 años.

- Enfermedades mentales contempladas en la clasificación que establece el RD 818/2009 (De los 11 apartados o grupos de trastornos mentales que recoge este Reglamento General, únicamente nos centraremos en la búsqueda bibliográfica de 8 grupos por considerar esta selección de mayor relevancia para el estudio. Los tres grupos de trastornos mentales eliminados por su inespecificidad son: trastornos mentales debidos a enfermedad médica no clasificados en otros apartados, otros trastornos mentales no incluidos en apartados anteriores y trastornos del control de los impulsos. (Ver tabla 2).

Los criterios de exclusión son:

- Enfermedad mental secundaria a condiciones laborales.

- Trabajadores por cuenta propia mayores de 65 años.

Tabla 2. Aptitudes psicofísicas requeridas para obtener o prorrogar la vigencia del permiso o de la licencia de conducción en trastornos mentales y de conducta.

\begin{tabular}{|c|c|c|c|c|}
\hline \multirow[b]{2}{*}{ Exploración (1) } & \multicolumn{2}{|c|}{$\begin{array}{l}\text { Criterios de aptitud para obtener o prorrogar } \\
\text { permiso o licenciade conducción ordinarios }\end{array}$} & \multicolumn{2}{|c|}{$\begin{array}{l}\text { Adaptaciones, restricciones y otras } \\
\text { limitaciones en personas, vehículos } \\
\text { o de circulación en permiso o licenci } \\
\text { sujetos a condiciones restrictivas }\end{array}$} \\
\hline & $\begin{array}{c}\text { Grupo 1: } \\
\text { AM,A1, A2, A, B, } \\
\text { B + E y LCC } \\
\text { (artículo 45.1a) (2) }\end{array}$ & $\begin{array}{c}\text { Grupo 2: } \\
\text { BTP, C1, C1 + } \\
\text { E, C, C + E, D1, } \\
\text { D1 + E, D, D } \\
+ \text { E (artículo } \\
\text { 45.1b y 2) (3) }\end{array}$ & Grupo 1 (4) & $\begin{array}{l}\text { Grupo } 2 \\
\text { (5) }\end{array}$ \\
\hline $\begin{array}{l}10.1 \text { Delirium, } \\
\text { demencia, trastornos } \\
\text { amnésicos y } \\
\text { otros trastornos } \\
\text { cognoscitivos. }\end{array}$ & $\begin{array}{l}\text { No deben existir supuestos de } \\
\text { delirium o demencia. Tampoco se } \\
\text { admiten casos de trastornos amné- } \\
\text { sicos u otros trastornos cognosciti- } \\
\text { vos que supongan un riesgo para } \\
\text { la conducción. }\end{array}$ & $\begin{array}{l}\text { No se } \\
\text { admiten. }\end{array}$ & $\begin{array}{l}\text { Cuando, excepcionalmente, y } \\
\text { con dictamen favorable de un neu- } \\
\text { rólogo o psiquiatra, no impidan la } \\
\text { obtención o prórroga, el período de } \\
\text { vigencia del permiso o licencia será } \\
\text { como máximo de un año. }\end{array}$ & $\begin{array}{l}\text { No se } \\
\text { admiten. }\end{array}$ \\
\hline $\begin{array}{l}\text { 10.2 Trastornos } \\
\text { mentales debidos a } \\
\text { enfermedad médica } \\
\text { no clasificados en } \\
\text { otros apartados. }\end{array}$ & $\begin{array}{l}\text { No deben existir trastornos ca- } \\
\text { tatónicos, cambios de personalidad } \\
\text { particularmente agresivos, u otros } \\
\text { trastornos que supongan un riesgo } \\
\text { para la seguridad vial. }\end{array}$ & $\begin{array}{l}\text { No se } \\
\text { admiten. }\end{array}$ & $\begin{array}{l}\text { Cuando, excepcionalmente, y con } \\
\text { dictamen favorable de un neurólogo } \\
\text { o psiquiatra, no impidan la obten- } \\
\text { ción o prórroga, el período de vigen- } \\
\text { cia del permiso o licencia será como } \\
\text { máximo de un año. }\end{array}$ & $\begin{array}{l}\text { No se } \\
\text { admiten. }\end{array}$ \\
\hline $\begin{array}{l}10.3 \text { Esquizofrenia } \\
\text { y otros trastornos } \\
\text { psicóticos. }\end{array}$ & $\begin{array}{l}\text { No debe existir esquizofrenia } \\
\text { o trastorno delirante. Tampoco se } \\
\text { admiten otros trastornos psicóti- } \\
\text { cos que presenten incoherencia o } \\
\text { pérdida de la capacidad asociativa, } \\
\text { ideas delirantes, alucinaciones o } \\
\text { conducta violenta, o que por alguna } \\
\text { otra razón impliquen riesgo para la } \\
\text { seguridad vial. }\end{array}$ & $\begin{array}{c}\text { Ídem } \\
\text { grupo } 1 .\end{array}$ & $\begin{array}{l}\text { Cuando, excepcionalmente, y } \\
\text { con dictamen favorable de un psi- } \\
\text { quiatra o psicólogo, no impidan la } \\
\text { obtención o prórroga, el período } \\
\text { de vigencia del permiso o licencia } \\
\text { será como máximo de un año. }\end{array}$ & $\begin{array}{c}\text { No se } \\
\text { admiten. }\end{array}$ \\
\hline
\end{tabular}




\begin{tabular}{|c|c|c|c|c|}
\hline \multirow[b]{2}{*}{ Exploración (1) } & \multicolumn{2}{|c|}{$\begin{array}{l}\text { Criterios de aptitud para obtener o prorrogar } \\
\text { permiso o licenciade conducción ordinarios }\end{array}$} & \multicolumn{2}{|c|}{$\begin{array}{l}\text { Adaptaciones, restricciones y otras } \\
\text { limitaciones en personas, vehículos } \\
\text { o de circulación en permiso o licenci } \\
\text { sujetos a condiciones restrictivas }\end{array}$} \\
\hline & $\begin{array}{c}\text { Grupo 1: } \\
\text { AM, A1, A2, A, B, } \\
\text { B + E y LCC } \\
\text { (artículo 45.1a) (2) }\end{array}$ & $\begin{array}{c}\text { Grupo 2: } \\
\text { BTP, C1, C1 + } \\
\text { E, C, C + E, D1, } \\
\text { D1 + E, D, D } \\
+ \text { E (artículo } \\
\text { 45.1b y 2) (3) }\end{array}$ & Grupo 1 (4) & $\begin{array}{l}\text { Grupo } 2 \\
\quad(5)\end{array}$ \\
\hline $\begin{array}{l}10.4 \text { Trastornos del } \\
\text { estado de ánimo. }\end{array}$ & $\begin{array}{l}\text { No deben existir trastornos gra- } \\
\text { ves del estado de ánimo que conlle- } \\
\text { ven alta probabilidad de conductas } \\
\text { de riesgo para la propia vida o la de } \\
\text { los demás. }\end{array}$ & $\begin{array}{l}\text { Ídem } \\
\text { grupo } 1 .\end{array}$ & $\begin{array}{l}\text { Cuando, excepcionalmente, exis- } \\
\text { ta dictamen de un psiquiatra o psicó- } \\
\text { logo favorable a la obtención o pró- } \\
\text { rroga, se podrá reducir el período } \\
\text { de vigencia del permiso o licencia } \\
\text { según criterio facultativo. }\end{array}$ & $\begin{array}{l}\text { Ídem } \\
\text { grupo } 1 .\end{array}$ \\
\hline $\begin{array}{l}\text { 10.5 Trastornos } \\
\text { disociativos. }\end{array}$ & $\begin{array}{l}\text { No deben admitirse aquellos } \\
\text { casos que supongan riesgo para la } \\
\text { seguridad vial. }\end{array}$ & $\begin{array}{l}\text { Ídem } \\
\text { grupo } 1 .\end{array}$ & $\begin{array}{l}\text { Cuando, excepcionalmente, exis- } \\
\text { ta dictamen de un psiquiatra o psi- } \\
\text { cólogo favorable a la obtención o } \\
\text { prórroga, se podrá reducir el perío- } \\
\text { do de vigencia del permiso o licen- } \\
\text { cia según criterio facultativo. }\end{array}$ & $\begin{array}{l}\text { Ídem } \\
\text { grupo } 1 .\end{array}$ \\
\hline $\begin{array}{l}10.6 \text { Trastornos del } \\
\text { sueño de origen no } \\
\text { respiratorio. }\end{array}$ & $\begin{array}{l}\text { No se admiten casos de narco- } \\
\text { lepsia o trastornos de hipersomnias } \\
\text { diurnas de origen no respiratorio, } \\
\text { ya sean primarias, relacionadas con } \\
\text { otro trastorno mental, enfermedad } \\
\text { médica o inducidas por sustancias. } \\
\text { Tampoco se admiten otros trastor- } \\
\text { nos del ritmo circadiano que su- } \\
\text { pongan riesgo para la actividad de } \\
\text { conducir. En los casos de insomnio } \\
\text { se prestará especial atención a los } \\
\text { riesgos asociados al posible consu- } \\
\text { mo de fármacos. }\end{array}$ & $\begin{array}{l}\text { Ídem } \\
\text { grupo } 1 .\end{array}$ & $\begin{array}{l}\text { Cuando, excepcionalmente, exis- } \\
\text { ta dictamen facultativo favorable a } \\
\text { la obtención o prórroga, se podrá } \\
\text { reducir el período de vigencia del } \\
\text { permiso o licencia según criterio } \\
\text { facultativo. }\end{array}$ & $\begin{array}{l}\text { Ídem } \\
\text { grupo } 1 .\end{array}$ \\
\hline $\begin{array}{l}10.7 \text { Trastornos } \\
\text { del control de los } \\
\text { impulsos. }\end{array}$ & $\begin{array}{l}\text { No se admiten casos de trastor- } \\
\text { nos explosivos intermitentes u otros } \\
\text { cuya gravedad suponga riesgo para } \\
\text { la seguridad vial. }\end{array}$ & $\begin{array}{l}\text { Ídem } \\
\text { grupo } 1 .\end{array}$ & $\begin{array}{l}\text { Cuando, excepcionalmente, exis- } \\
\text { ta dictamen de un psiquiatra o psi- } \\
\text { cólogo favorable a la obtención o } \\
\text { prórroga, se podrá reducir el perío- } \\
\text { do de vigencia del permiso o licen- } \\
\text { cia según criterio facultativo. }\end{array}$ & $\begin{array}{c}\text { Ídem } \\
\text { grupo } 1 .\end{array}$ \\
\hline $\begin{array}{l}10.8 \text { Trastornos de la } \\
\text { personalidad. }\end{array}$ & $\begin{array}{l}\text { No deben existir trastornos gra- } \\
\text { ves de la personalidad, en particular } \\
\text { aquellos que se manifiesten en con- } \\
\text { ductas antisociales con riesgo para } \\
\text { la seguridad de las personas. }\end{array}$ & $\begin{array}{l}\text { Ídem } \\
\text { grupo } 1 .\end{array}$ & $\begin{array}{l}\text { Cuando, excepcionalmente, } \\
\text { exista dictamen de un psiquiatra o } \\
\text { psicólogo favorable a la obtención } \\
\text { o prórroga, se podrá reducir el pe- } \\
\text { ríodo de vigencia del permiso o li- } \\
\text { cencia según criterio facultativo. }\end{array}$ & $\begin{array}{l}\text { Ídem } \\
\text { grupo } 1 .\end{array}$ \\
\hline \multirow[t]{2}{*}{$\begin{array}{l}\text { 10.9 Trastornos } \\
\text { del desarrollo } \\
\text { intelectual. }\end{array}$} & $\begin{array}{l}\text { No debe existir retraso mental } \\
\text { con cociente intelectual inferior } \\
\text { a } 70 \text {. }\end{array}$ & $\begin{array}{c}\text { No debe } \\
\text { existir retraso } \\
\text { mental con } \\
\text { un cociente } \\
\text { intelectual } \\
\text { inferior a } 70 .\end{array}$ & No se admiten. & $\begin{array}{c}\text { No se } \\
\text { admiten. }\end{array}$ \\
\hline & $\begin{array}{l}\text { En los casos de retraso mental } \\
\text { con cociente intelectual entre } 50 \text { y } \\
70 \text {, se podrá obtener o prorrogar } \\
\text { si el interesado acompaña un dic- } \\
\text { tamen favorable de un psiquiatra o } \\
\text { psicólogo. }\end{array}$ & $\begin{array}{c}\text { No se } \\
\text { admiten. }\end{array}$ & $\begin{array}{l}\text { Cuando el dictamen del psiquia- } \\
\text { tra o psicólogo sea favorable a la } \\
\text { obtención o prórroga, se podrán } \\
\text { establecer condiciones restrictivas } \\
\text { según criterio facultativo. }\end{array}$ & $\begin{array}{l}\text { No se } \\
\text { admiten. }\end{array}$ \\
\hline
\end{tabular}




\begin{tabular}{|c|c|c|c|c|}
\hline \multirow[b]{2}{*}{ Exploración (1) } & \multicolumn{2}{|c|}{$\begin{array}{l}\text { Criterios de aptitud para obtener o prorrogar } \\
\text { permiso o licenciade conducción ordinarios }\end{array}$} & \multicolumn{2}{|c|}{$\begin{array}{l}\text { Adaptaciones, restricciones y otras } \\
\text { limitaciones en personas, vehículos } \\
\text { o de circulación en permiso o licenci } \\
\text { sujetos a condiciones restrictivas }\end{array}$} \\
\hline & $\begin{array}{c}\text { Grupo 1: } \\
\text { AM, A1, A2, A, B } \\
\text { B + E y LCC } \\
\text { (artículo 45.1a) (2) }\end{array}$ & $\begin{array}{c}\text { Grupo 2: } \\
\text { BTP, C1, C1 + } \\
\text { E, C, C + E, D1, } \\
\text { D1 + E, D, D } \\
\text { + E (artículo } \\
\text { 45.1b y 2) (3) }\end{array}$ & Grupo 1 (4) & $\begin{array}{l}\text { Grupo } 2 \\
\text { (5) }\end{array}$ \\
\hline $\begin{array}{l}10.10 \text { Trastornos por } \\
\text { déficit de atención } \\
\text { y comportamiento } \\
\text { perturbador. }\end{array}$ & $\begin{array}{l}\text { No deben existir trastornos por } \\
\text { déficit de atención cuya gravedad } \\
\text { implique riesgo para la conducción. } \\
\text { Tampoco se admiten casos modera- } \\
\text { dos o graves de trastorno disocial } \\
\text { u otros comportamientos perturba- } \\
\text { dores acompañados de conductas } \\
\text { agresivas o violaciones graves de } \\
\text { normas cuya incidencia en la segu- } \\
\text { ridad vial sea significativa. }\end{array}$ & $\begin{array}{c}\text { Ídem } \\
\text { grupo } 1 .\end{array}$ & $\begin{array}{l}\text { Cuando, excepcionalmente, } \\
\text { exista dictamen de un psiquiatra o } \\
\text { psicólogo favorable a la obtención } \\
\text { o prórroga, se podrá reducir el pe- } \\
\text { ríodo de vigencia del permiso o li- } \\
\text { cencia según criterio facultativo. }\end{array}$ & $\begin{array}{l}\text { No se } \\
\text { admiten. }\end{array}$ \\
\hline $\begin{array}{l}10.11 \text { Otros } \\
\text { trastornos mentales } \\
\text { no incluidos en } \\
\text { apartados anteriores. }\end{array}$ & $\begin{array}{l}\text { No deben existir trastornos diso- } \\
\text { ciativos, adaptativos u otros proble- } \\
\text { mas objeto de atención clínica que } \\
\text { sean funcionalmente incapacitantes } \\
\text { para la conducción. }\end{array}$ & $\begin{array}{c}\text { Ídem } \\
\text { grupo } 1 .\end{array}$ & $\begin{array}{l}\text { Cuando exista dictamen de un } \\
\text { psiquiatra o psicólogo favorable a } \\
\text { la obtención o prórroga, se podrá } \\
\text { reducir el período de vigencia del } \\
\text { permiso o licencia según criterio } \\
\text { facultativo. }\end{array}$ & $\begin{array}{c}\text { Ídem } \\
\text { grupo } 1 .\end{array}$ \\
\hline
\end{tabular}

A la hora de la búsqueda bibliográfica no se ha tenido en cuenta si los sujetos incluidos en el estudio estaban bajo el efecto de medicación alguna.

A cada uno de los efectos estudiados en los distintos artículos se les asignó un nivel de evidencia científica de acuerdo con los criterios de la Scottish Intercollegiate Guidelines Network (SIGN). (Anexo II)

La búsqueda se complementó mediante consultas específicas a determinadas páginas web de Internet: Dirección General de Tráfico (DGT), Diagnostic and Statistical Manual of Mental Disorders (DSM IV), Ministerio de Sanidad y Política Social e Igualdad, Ministerio del Interior, Ministerio de Fomento, Boletín oficial del Estado (BOE).

También se han revisado en este trabajo los textos de la ley orgánica (Ley 17/2005, de 19 de julio, por la que se regula el permiso y la licencia de conducción por puntos y se modifica el texto articulado de la ley sobre tráfico, circulación de vehículos a motor y seguridad vial, especialmente el RD 818/2009, de 8 de mayo, por el que se aprueba el Reglamento General de Conductores) y el RD 1032/2007 de 20 de julio, por el que se regula la cualificación inicial y la formación continua de los conductores de determinados vehículos destinados al transporte por carretera (BOE 02-08). Igualmente se han revisado los textos del RD 1/1994 (Art. 115) de la Ley General de la Seguridad Social y del artículo 63 del RD 339/1990 de 2 marzo.

\section{RESULTADOS}

De los 744 artículos encontrados inicialmente se han seleccionado 19 para revisión a texto completo de acuerdo a los criterios de inclusión y exclusión establecidos, quedando finalmente 17 artículos reflejados en los resultados. Cuatro artículos seleccionados fueron pedidos y no suministrados.

A continuación exponemos, siguiendo la clasificación de enfermedades mentales que establece el RD 818/2009, las definiciones de dichos trastornos según el DSM IV y 
los resultados extraídos de la revisión de los artículos obtenidos en la búsqueda bibliográfica:

\section{Delirium, demencia, trastornos amnésicos y otros trastornos cognoscitivos}

El Diagnostic and Statistical Manual of Mental Disorders (DSM IV) los define como un déficit clínicamente significativo en las funciones cognoscitivas o en la memoria que representa un cambio en relación con el nivel previo de actividad.

Criterios de aptitud para obtener o prorrogar el permiso o licencia de conducción ordinarios: El RD 818/2009 establece para los carnés del Grupo 1 y 2 que no deben existir supuestos de delirium, demencia, trastornos amnésicos u otros trastornos cognoscitivos que supongan un riesgo para la conducción.

Si existen adaptaciones, restricciones y otras limitaciones en personas, el RD 818/2009 establece para el Grupo 1 que cuando excepcionalmente, y con dictamen favorable de un neurólogo o psiquiatra, no impidan la obtención o prorroga, el periodo de vigencia del permiso o licencia será como máximo de un año. Para el Grupo 2 no se admite periodo de vigencia.

Tabla 3. Publicaciones analizadas sobre delirium, demencia, trastornos amnésicos y otros trastornos cognoscitivos.

\begin{tabular}{|c|c|c|c|c|c|}
\hline $\begin{array}{l}\text { Primer autor/ } \\
\text { año/ref }\end{array}$ & $\begin{array}{l}\text { Tipo de } \\
\text { diseño }\end{array}$ & $\begin{array}{l}\text { Variable } \\
\text { resultado }\end{array}$ & $\begin{array}{l}\mathrm{N}^{\circ} \mathrm{de} \\
\text { casos }\end{array}$ & Resultados & $\begin{array}{l}\text { Nivel de } \\
\text { evidencia }\end{array}$ \\
\hline $\begin{array}{l}\text { Bádanes, D } \\
2008 \\
(4)\end{array}$ & $\begin{array}{l}\text { Estudio } \\
\text { transversal }\end{array}$ & $\begin{array}{l}\text { Enfermos con DL } \\
\text { y DCL y sanos. } \\
\text { Aptitud }\end{array}$ & 184 & $\begin{array}{l}\text { DL: } 90 \% \text { no superan test. } \\
\text { DCL: } 50 \% \text { no superan. }\end{array}$ & 3 \\
\hline
\end{tabular}

Ante el consenso general, según la International Consensus Conference on Dementia and Driving, de que las personas con demencia moderada y grave no conduzcan y de que es preciso una mayor valoración en las demencias leves (DL), Bádanes $\mathrm{D}^{4}$, hace un estudio transversal con casos leves de demencia y deterioro cognitico leve (DCL). Se establecen inicialmente puntos de corte para valorar la sensibilidad y especificidad de los test psicotécnicos ASDE y UFOV (Usefull Field of View) que posteriormente se aplicaran a los casos a estudio.

En los resultados se observa que es preciso aplicar el test ASDE al completo para detectar los trastornos cognitivos, pero también según estos autores generalmente esto no suele llevarse a cabo en los centros de renovación. Se detecta que el $50 \%$ de los pacientes con Deterioro Cognitivo leve pueden conducir (aunque la especificidad y sensibilidad de los test es inferior a 70\%), pero no se aconseja en el DCL Múltiples Funciones. Concluye que el $90 \%$ de los pacientes con demencia leve no debieran conducir. En ambos casos sería necesario hacer un seguimiento estrecho de los pacientes.

En la demencia inicial ${ }^{4}$ se ven las dificultades que estos pacientes presentan a la hora de superar las pruebas psicotécnicas para la conducción. Aunque en menor grado, se observa lo mismo para los deterioros cognitivos leves. Este estudio podría acercarse a la revisión de Breen DA y col $^{5}$ que habla de la asociación de la demencia con el aumento de los accidentes de circulación, pero también de la posibilidad de conducir en ciertos casos a los inicios de la enfermedad. De acuerdo con el RD 818/2009 estos pacientes no debieran conducir. Aunque en algunos casos, como en la demencia leve o inicial y el deterioro cognitivo leve, exceptuando los de Múltiples Funciones, necesitarían de una mayor valoración por los especialistas. No hay estudios que indiquen la actitud a tomar con los conductores profesionales, aunque el Reglamento Español no admite estos casos. 


\section{Trastornos de la personalidad}

Patrón permanente e inflexible de experiencia interna y de comportamiento que se adapta acusadamente de las expectativas de la cultura del sujeto. Tiene su inicio en la adolescencia o principio de la edad adulta y conlleva malestar o perjuicios para el sujeto.

Criterios de aptitud para obtener o prorrogar el permiso o licencia de conducción ordinarios: El RD 818/2009 establece que para los carnés de los grupos 1 y 2 no deben existir trastornos graves de la personalidad, sobre todo aquellos que cursan con conductas antisociales con riesgo para la seguridad de las personas. Tampoco deben existir cambios de la personalidad particularmente agresivos que supongan un riesgo para la seguridad vial.

Como adaptaciones o restricciones se podrá reducir el período de vigencia del permiso de conducir siempre que exista un dictamen de un especialista (psiquiatra o psicólogo) favorable en este sentido, tanto para los grupos 1 y 2 .

Tabla 4. Publicaciones analizadas sobre trastornos de la personalidad.

\begin{tabular}{|c|c|c|c|c|c|}
\hline $\begin{array}{c}\text { Primer autor/ } \\
\text { año/ref }\end{array}$ & $\begin{array}{l}\text { Tipo de } \\
\text { diseño }\end{array}$ & Variable resultado & $\begin{array}{l}\mathbf{N}^{\circ} \text { de } \\
\text { casos }\end{array}$ & Resultados & $\begin{array}{c}\text { Nivel de } \\
\text { evidencia }\end{array}$ \\
\hline $\begin{array}{l}\text { Nabi H } \\
2006 \\
(6)\end{array}$ & $\begin{array}{l}\text { Cohortes } \\
\text { prospectivo }\end{array}$ & $\begin{array}{l}\text { Personalidad agresiva } \\
\text { y hostil y accidentes } \\
\text { con heridos }\end{array}$ & 11.754 & $\begin{array}{l}\text { Asociación entre conductas } \\
\text { agresivas e irritabilidad } \\
\text { y accidentes de tráfico. }\end{array}$ & $2+$ \\
\hline $\begin{array}{l}\text { Dumais A } \\
2005 \\
(7)\end{array}$ & $\begin{array}{l}\text { Casos y } \\
\text { controles }\end{array}$ & $\begin{array}{l}\text { Factores de riesgo } \\
\text { psiquiátricos y } \\
\text { accidentes en hombres } \\
\text { jóvenes }\end{array}$ & 122 & $\begin{array}{l}\text { Trastornos de la } \\
\text { personalidad del grupo B } \\
\text { y abuso de alcohol y otras } \\
\text { sustancias relacionados con } \\
\text { mayor tasa de accidentes de } \\
\text { tráfico. }\end{array}$ & $2+$ \\
\hline
\end{tabular}

En el estudio de cohortes de Nabi $\mathrm{H}^{6}$ se siguió durante siete años $(1994-2001)$ a una cohorte de trabajadores franceses (GAZEL) para esclarecer si las variables psicométricas de agresivdad, hostilidad, etc se asocian significativamente con un mayor riesgo de accidentes de tráfico. Para ello se les pasó la encuesta BDHI (versión francesa de BussDurkee Hostility Inventory) que valora distintas características de personalidad. En puntuaciones altas e intermedias de las variables irritabilidad y negativismo se vio que éstas tienen una asociación significativa con padecer algún accidente de tráfico. Los riesgos relativos fueron respectivamente para irritabilidad del 1.29 (95\% CI: 1.00-1.68) y para negativismo 1.29 (95\% CI: 1.00-1.66) con una $\mathrm{p}=0.004$. Sin embargo en puntuaciones bajas de estas variables no se halló una asociación significativa. Ajustando por sexo, edad, ocupación, el RR aumentó ligeramente y reportó aún mayor asociación.

De ello se concluye que hay una asociación leve pero significativa entre la irritabilidad y el negativismo, entendido éste como el comportamiento de oposición a la autoridad o la negativa a colaborar y acatar normas, y los accidentes de tráfico, ya que los individuos con alta irritabilidad son más propensos a tener conductas agresivas que pueden afectar negativamente al proceso de toma de decisiones ante situaciones irritantes (luces agresivas, gestos obscenos, abuso de aproximarse en exceso al coche de delante, agresiones verbales, etc). La causa de la asociación negativismo/accidentes de tráfico puede radicar en que estas personas se creen con el derecho de poder impugnar aquellas normas que consideran arbitrarias o injustas.

En el estudio de casos y controles de Dumais $\mathbf{A}^{7}$, en el que se determina la relación entre factores de riesgo psiquiátricos y los accidentes de vehículo a motor, se vio que los trastornos de personalidad límite y antisocial, (grupo B DSM IV) en los que predominan los rasgos de impulsividad y agresividad, y los trastornos derivados del consumo de sustancias aumentan el riesgo de muerte por accidente de tráfico (OR 3.54; 95\%CI, (1.38 - 16.01) para los primeros y OR 4.33; 95\%CI, (1.42 - 9.25) para los segundos). Un $41 \%$ de 
los casos (víctimas de accidente de tráfico) asociaron tener algún trastorno de la personalidad tipo B frente al $16.4 \%$ de los controles. También se observó, ajustando el estudio, un efecto de edad (OR 16.25; 95\%CI, 1.67 - 158.10) ya que un 22.6\% de los casos menores de 26 años presentó algún trastorno de la personalidad tipo B frente al $60 \%$ de casos con estos trastornos mayores de 26 años. Esto se explica porque en la franja de edad de 25 a 34 años la tasa de frecuencia de consumo de alcohol y otras drogas es mayor, al igual que la prevalencia de trastornos de la personalidad del grupo B (se ha demostrado que estos trastornos de la personalidad aumentan la posibilidad de desarrollar un trastorno por consumo de sustancias, lo que conllevaría un mayor riesgo de muerte por accidente de tráfico), en contra del grupo de conductores más jóvenes, donde la accidentabilidad en la carretera viene determinada en mayor grado por su inexperiencia al volante.

Así pues, con los resultados obtenidos en estos estudios se puede determinar que algunos trastornos de personalidad, sobre todo los que cursan con conductas antisociales, se relacionan con una mayor probabilidad de tener accidentes de tráfico, estando en consonancia, por tanto, con lo que dice el RD 818/2009.

\section{Trastornos por déficit de atención y comportamiento perturbador}

Se trata de un trastorno del comportamiento caracterizado por distracción moderada a severa, períodos de atención breve, inquietud motora, inestabilidad emocional y conductas impulsivas. Esta disfunción neurobiológica fue reconocida primero en la edad infantil. Sin embargo, en la medida en que fue mejor comprendida, se reconoció su carácter crónico, ya que persiste y se manifiesta más allá de la adolescencia. Los estudios de seguimiento a largo plazo han demostrado que entre el $60 \%$ y el $75 \%$ de los niños con Trastorno por déficit de Atención e Hiperactividad (TDAH) continúan presentando los síntomas hasta la vida adulta.

Criterios de aptitud para obtener o prorrogar el permiso o licencia de conducción ordinarios: El RD 818/2009 establece tanto para los grupos de conductores 1 y 2 que no deben existir trastornos por déficit de atención cuya gravedad implique riesgo para la conducción. Tampoco se admitirán casos moderados o graves de trastorno disocial u otros comportamientos perturbadores acompañados de conductas agresivas o violaciones graves de normas cuya incidencia en la seguridad vial sea significativa.

Se admitirán adaptaciones en el grupo 1 cuando, excepcionalmente, exista un dictamen de un facultativo (psiquiatra o psicólogo) favorable en este sentido. Sin embargo no se admitirán adaptaciones o restricciones para el grupo de conductores profesionales (grupo 2).

Tabla 5. Publicaciones analizadas sobre trastornos por déficit de atención y comportamiento perturbador.

\begin{tabular}{|c|c|c|c|c|c|}
\hline $\begin{array}{l}\text { Primer autor/ } \\
\text { año/ref }\end{array}$ & $\begin{array}{l}\text { Tipo de } \\
\text { diseño }\end{array}$ & Variable resultado & $\begin{array}{l}\mathbf{N}^{\circ} \text { de } \\
\text { casos }\end{array}$ & Resultados & $\begin{array}{l}\text { Nivel de } \\
\text { evidencia }\end{array}$ \\
\hline $\begin{array}{l}\text { Thompson } \\
\text { A L. } \\
2007\end{array}$ & Trasnversal & $\begin{array}{l}\text { Capacidad para } \\
\text { conducir con TDAH }\end{array}$ & 355 & $\begin{array}{l}\text { Los TDAH aumentan el } \\
\text { riesgo de lesiones por } \\
\text { accidente de tráfico. }\end{array}$ & 3 \\
\hline
\end{tabular}

(8)

Reimer B. Transversal Conducción y tareas

Weafer J. 2008

(10)
Transversal TDAH e intoxicación por alcohol
60

La capacidad para conducir se ve mermada durante la realización de tareas secundarias en condiciones de poca exigencia de niveles de atención.

38 Los conductores con TDAH presentan similares niveles de atención a conductores intoxicados por alcohol. 
El estudio de Thompson $\mathrm{AL}^{8}$ concluye que el TDAH en la infancia eleva el riesgo de padecer problemas relacionados con la conducción, especialmente cuando los síntomas persisten (el 66\% de niños con TDAH cronifican sus síntomas a la edad adulta). Los adolescentes y adultos jóvenes diagnosticados de TDAH tienen más riesgo de sufrir accidentes de tráfico o de padecer lesiones relacionadas con el automóvil. También son más propensos a presentar un comportamiento de conducción de riesgo y a percibir más multas por infracciones.

El TDAH en el adulto está asociado a altos niveles de morbilidad y deterioro funcional. Reimer $\mathrm{B}^{9}$ estudia el impacto de las tareas cognitivas secundarias a la hora de conducir en personas con y sin TDAH. Los conductores con TDAH se ven involucrados en accidentes de tráfico con más frecuencia en comparación con conductores sin esta patología (58\% de los casos (conductores con TDAH) sufrieron algún accidente de tráfico en los cinco años previos al estudio frente al 34\% de controles (conductores sin esta patología). También se vio que los conductores jóvenes o menos experimentados se ven implicados con mayor frecuencia en accidentes de tráfico relacionados con la falta de atención. En condiciones de alta demanda de atención en la conducción los conductores con TDAH muestran más dificultades en su capacidad para conducir durante la realización de tareas cognitivas secundarias como el manejo del teléfono. Por el contrario, en condiciones de baja demanda de atención, la capacidad de conducción sí se mostraba alterada durante la ejecución de tareas secundarias.

Según Weafer $\mathrm{J}^{10}$ los conductores con TDAH presentan niveles de atención durante la conducción similares a los de conductores sin TDAH ebrios, es decir, la toxicidad por alcohol disminuye los niveles de atención durante la conducción causando déficits cognitivos y conductuales que pueden equipararse a los causados por un TDAH. Por otro lado, los efectos de los niveles de alcoholemia tienen un efecto sumatorio a los causados por un TDAH, (aún en cifras de alcoholemia permitidas por la ley), por lo que la probabilidad de sufrir un accidente de tráfico en estas personas aumenta.

Según los resultados obtenidos, los conductores con TDAH tienen mayor riesgo de tener accidentes de tráfico, por lo que apoyan lo establecido en el RD 818/2009.

\section{Esquizofrenia y otros trastornos psicóticos}

Es un trastorno mental que dificulta establecer la diferencia entre experiencias reales e irreales, pensar de manera lógica, tener respuestas emocionales normales y comportarse normalmente en situaciones sociales.

Criterios de aptitud para obtener o prorrogar el permiso o licencia de conducción ordinarios: El RD 818/2009 dice que para los grupos 1 y 2 no debe existir esquizofrenia ni trastorno delirante. Tampoco se admiten otros trastornos psicóticos que presenten incoherencia, pérdida de la capacidad asociativa, ideas delirantes, alucinaciones o conducta violenta; o que por alguna otra razón implique riesgo para la seguridad vial.

Se admitirán adaptaciones excepcionalmente con un dictamen favorable de un neurólogo o psiquiatra y el período de vigencia máximo será de un año (grupo 1). No se admiten adaptaciones para el grupo 2 .

En el estudio observacional11 queda patente que una vez aflorada la patología psiquiátrica solo el $1 \%$ de los conductores consigue la renovación del permiso de conducción, a nivel usuario, nunca a nivel profesional. Y siempre tras un periodo libre de síntomas de dos años desde de la última recaída.

En los trastornos de ansiedad normalmente no hay razón para la descalificación, a menos que tengan regularmente ataques de pánico resistentes al tratamiento, o que desencadenen trastornos disociativos que puedan llevar a la incapacidad, los pacientes con recidiva que sufren fuga psicógena grave y trastornos de la personalidad severos no son aptos para ninguna licencia ya que han demostrado una clara falta de responsabilidad social. No obstante los criterios, modificados en 2008, recogen que hay ciertas condiciones especiales en las que podrían conservar el permiso, incluso si el paciente utiliza psicoestimulantes, estando referenciado por el informe de un psicólogo o psiquiatra ${ }^{12,13}$. 
Según el informe del 2000, sobre "La salud y el tráfico" elaborado por el Ministerio Federal de Transportes, Construcción y Vivienda y el Ministerio Federal de Salud Alemán, en el artículo titulado "Directrices para la evaluación de la aptitud para conducir" se determinan los requerimientos para obtener la licencia y para la seguridad vial en el trabajo e incluye por primera vez directrices médicas y psicológicas, de aptitud para la conducción ${ }^{14}$.

Tabla 6. Publicaciones analizadas sobre esquizofrenia y otros trastornos psicóticos.

\begin{tabular}{|c|c|c|c|c|c|}
\hline $\begin{array}{l}\text { Primer autor/ } \\
\text { año/ref }\end{array}$ & $\begin{array}{l}\text { Tipo de } \\
\text { diseño }\end{array}$ & Variable resultado & $\begin{array}{l}\mathrm{N}^{\circ} \mathrm{de} \\
\text { casos }\end{array}$ & Resultados & $\begin{array}{l}\text { Nivel de } \\
\text { evidencia }\end{array}$ \\
\hline $\begin{array}{l}\text { Inglott, R. } \\
2004 \\
(11)\end{array}$ & $\begin{array}{l}\text { Estudio } \\
\text { transversal }\end{array}$ & $\begin{array}{l}\text { Esquizofrenia } \\
\text { y Capacidad de } \\
\text { conducción }\end{array}$ & 651 & $\begin{array}{l}\text { El } 1 \% \text { de los pacientes } \\
\text { consigue la renovación } \\
\text { del carnet }\end{array}$ & 3 \\
\hline $\begin{array}{l}\text { Gómez } \\
\text { Esteban, R. } \\
2003 \\
(12)\end{array}$ & $\begin{array}{l}\text { Estudio } \\
\text { transversal }\end{array}$ & $\begin{array}{l}\text { Esquizofrenia y } \\
\text { actividades de la vida } \\
\text { diaria }\end{array}$ & 12 & $\begin{array}{l}\text { La psicoterapia de grupo, } \\
\text { es una herramienta útil y } \\
\text { combinada con obtiene } \\
\text { resultados favorables. }\end{array}$ & 3 \\
\hline $\begin{array}{l}\text { Odegaard, } \\
\text { O } \\
1956 \\
(13)\end{array}$ & $\begin{array}{l}\text { Estudio } \\
\text { observa- } \\
\text { cional } \\
\text { de corte } \\
\text { retrospectivo }\end{array}$ & $\begin{array}{l}\text { Esquizofrenia y aptitud } \\
\text { para trabajar }\end{array}$ & 489 & $\begin{array}{l}\text { Concluye que la relación } \\
\text { entre enf. mental y } \\
\text { diferentes profesiones se } \\
\text { debe a causas ambientales y } \\
\text { factores sociales. }\end{array}$ & 3 \\
\hline $\begin{array}{l}\text { Laux G } \\
2002 \\
(14)\end{array}$ & $\begin{array}{l}\text { Revisión } \\
\text { bibliográfica }\end{array}$ & $\begin{array}{l}\text { Pacientes psiquiátricos y } \\
\text { conducción }\end{array}$ & 231 & $\begin{array}{l}\text { Marco jurídico y regulación } \\
\text { de la licencia para la } \\
\text { conducción en pacientes } \\
\text { psiquiátricos. }\end{array}$ & 3 \\
\hline $\begin{array}{l}\text { De Wolf, } \\
\text { M.M. } \\
2010 \\
(15)\end{array}$ & $\begin{array}{l}\text { Revisión } \\
\text { bibliográfica }\end{array}$ & $\begin{array}{l}\text { Pacientes psiquiátricos } \\
\text { y aptitud para la } \\
\text { conducción }\end{array}$ & 52 & $\begin{array}{l}\text { Legislación en conductores } \\
\text { con patología psiquiátrica. }\end{array}$ & 3 \\
\hline $\begin{array}{l}\text { Gómez } \\
\text { Talegón, } \\
\text { M. T. } \\
2008 \\
\text { (16) }\end{array}$ & $\begin{array}{l}\text { Estudio } \\
\text { tranversal }\end{array}$ & $\begin{array}{l}\text { Aptitud para conducir } \\
\text { de los pacientes con } \\
\text { trastornos mentales: } \\
\text { evaluación }\end{array}$ & 5.234 & $\begin{array}{l}\text { Cada enfermo psiquiátrico, } \\
\text { debe ser analizado de } \\
\text { manera individual. }\end{array}$ & 3 \\
\hline
\end{tabular}

Las normas para la evaluación de la aptitud para conducir con trastornos psiquiátricos en los Países Bajos son bastante clara: el paciente psiquiátrico, tiene el deber moral de dar a conocer su patología ante la mínima duda sobre su capacidad, si es profesional de la conducción. El psiquiatra o médico de cabecera deberían poder dar el apto o no con estos datos para el no profesional, aunque no se disponga de unos criterios regulados ${ }^{15}$.

En psicosis esquizofrénica aguda el permiso de conducción no se da a ningún grupo ya que no se cumplen los requisitos para la seguridad vial. Después de expirado, en psicosis aguda, podría reevaluarse para el Grupo 1, si no hay síntomas graves de psicosis, como delirios, alucinaciones o deterioro cognitivo grave detectable. Con un informe psiquiátrico favorable se podría reconsiderar, o tras la estabilización con neurolépticos y antipsicóticos bajo algunas restricciones. En un estudio realizado a 19 pacientes esquizofrénicos en el momento del alta hospitalaria solo dos obtuvieron la licencia y del análisis posterior de los datos se concluyó que existe una enorme variabilidad individual, pero solo el $10 \%$ de los pacientes esquizofrénicos dados de alta se encuentran en un estado estacionario de la enfermedad ${ }^{16}$.

En el tema de la esquizofrenia y los trastornos disociativos el RD 818/2009 es claro no permite la conducción, y se ha constatado en las publicaciones revisadas que ciertamente los pacientes con estos trastornos son en su mayoría incapaces de ser 
completamente autónomos en sus actividades de la vida diaria, y por tanto no son aptos para la conducción ya que supondrían un grave peligro para la seguridad vial. También es cierto que hay otro grupo aunque más reducido de pacientes, con una sintomatología más leve que responde muy bien al tratamiento, y que con un seguimiento médico estrecho podrían obtener un permiso de conducción bajo algunas restricciones, y siempre a nivel de usuario nunca profesional.

\section{Trastornos disociativos}

Se caracterizan por una pérdida parcial o completa de la integración psíquica normal, en especial de la memoria y de la conciencia de la propia identidad o personalidad. Obedecen a un origen probablemente psicógeno y muestran una estrecha relación temporal con acontecimientos traumáticos, problemas insolubles, insoportables o relaciones interpersonales alteradas. Su formulación diagnóstica implica malestar clínico significativo o deterioro en el plano social, laboral o en otras áreas del desarrollo personal. Se conserva intacto el contacto con la realidad.

Criterios de aptitud para obtener o prorrogar el permiso o licencia de conducción ordinarios: $\mathrm{El} \mathrm{RD}$ establece que no deben admitirse aquellos casos que supongan riesgos para la seguridad vial (grupos 1 y 2 )

Se harán adaptaciones cuando excepcionalmente exista un dictamen de un psiquiatra o psicólogo favorable a la obtención de prórroga. Se podrá reducir el período de vigencia de permiso o licencia según criterio facultativo. (Grupos 1 y 2).

No se han encontrado artículos pertinentes relacionados con este tema ya que en todos se cruzaban los trastornos disociativos con alcoholismo.

\section{Trastornos del sueño de origen no respiratorio}

Se trata de un grupo de trastornos que cursan con alteración del ciclo del sueño ya sean de origen primario o derivados de otros trastornos mentales, enfermedad médica o por consumo de sustancias.

Criterios de aptitud para obtener o prorrogar el permiso o licencia de conducción ordinarios: El RD establece tanto para el grupo 1 y 2 que no se admiten casos de narcolepsia o trastornos de hipersomnias diurnas de origen no respiratorio, ya sean respiratorias, relacionadas con otro trastorno mental, enfermedad médica o inducida por sustancias. Tampoco se admiten otros trastornos del ciclo circadiano que supongan riesgo para la actividad de conducir. En los casos de insomnio se prestará especial atención a los riesgos asociados al posible consumo de fármacos.

Tanto para los grupos 1 y 2 se podrán hacer adaptaciones siempre y cuando excepcionalmente exista un dictamen de un psiquiatra o psicólogo favorable a la obtención de prórroga pudiendo reducir el período de vigencia de permiso o licencia según criterio facultativo.

Findley $\mathrm{L}^{17}$, en un estudio transversal en pacientes con Apnea del Sueño y Narcolepsia no tratada analiza la relación existente entre el trastorno de la vigilancia en la conducción y la asociación al riesgo de accidentes de tráfico en estos pacientes. Para ello somete a los casos ( $n=10$ en narcolepsia), controles ( $n=10$ en narcolepsia) y voluntarios $(n=10$ en narcolepsia) a un test de vigilancia en la conducción por ordenador consistente en evitar obstáculos. Posteriormente, y en relación al porcentaje de obstáculos no salvados, se clasificó el rendimiento de los participantes en "normal", "pobre" o "muy pobre rendimiento".

Los resultados del estudio mostraron que los pacientes con narcolepsia presentaban un mayor porcentaje de fallos $(7.7 \pm 3.2 \%)$ que los controles $(1.2 \pm 0.3 \%$; $<0.05)$ y los voluntarios $(0.9 \pm 0.05 \% ; \mathrm{p}<0.05)$. No se encontró significación estadística entre la severidad de la narcolepsia y el grado de rendimiento en el test de obstáculos. Si hubo asociación estadística entre el grado de rendimiento en el test de vigilancia y la tasa de accidentes 
de automóvil ( $\mathrm{p}<0.01)$. Mientras que en el grupo de pacientes con "normal rendimiento" tuvieron 1 accidente en 5 años (0.05 accidentes/conductor/5 años), en el de "pobre rendimiento" y "muy pobre rendimiento" fueron de 5 y 8 accidentes en 5 años $(0.20$ y 0.38 accidentes/conductor/5 años) respectivamente. Los pacientes con "muy pobre rendimiento" en el test obtenían una tasa significativamente mayor de accidentes de automóvil que los pacientes con "menor rendimiento" $(\mathrm{p}<0.05)$. Los autores concluyen que la narcolepsia puede llevar a un bajo rendimiento en la conducción y en consecuencia a un mayor peligro para accidentes de automóvil.

Tabla 7. Publicaciones analizadas sobre trastornos del sueño de origen no respiratorio.

\begin{tabular}{|c|c|c|c|c|c|}
\hline $\begin{array}{l}\text { Primer autor/ } \\
\text { año/ref }\end{array}$ & $\begin{array}{l}\text { Tipo de } \\
\text { diseño }\end{array}$ & Variable resultado & $\mathrm{N}^{\circ}$ de casos & Resultados & $\begin{array}{l}\text { Nivel de } \\
\text { evidencia }\end{array}$ \\
\hline $\begin{array}{l}\text { Findley L } \\
1995 \\
(17)\end{array}$ & Transversal & $\begin{array}{l}\text { Narcolepsia Acccidente } \\
\text { de coche } \\
\text { Fallos en la vigilancia }\end{array}$ & $\begin{array}{c}10 \\
\text { casos } \\
10 \\
\text { controles } \\
10 \\
\text { voluntarios }\end{array}$ & $\begin{array}{l}\% \text { de fallos en el test con } \\
\text { narcolepsia mayores que } \\
\text { en controles. Rendimiento } \\
\text { en test y accidentes de } \\
\text { automóvil ( } \mathrm{p}<0.01 \text { ). } \\
\text { Narcolepsia } \uparrow \text { accidentes. }\end{array}$ & 3 \\
\hline $\begin{array}{l}\text { Murray TJ } \\
1974 \\
(18)\end{array}$ & $\begin{array}{l}\text { Revisión de } \\
\text { casos }\end{array}$ & $\begin{array}{l}\text { Narcolepsia y accidentes } \\
\text { de tráfico }\end{array}$ & & $\begin{array}{l}\text { La narcolepsia es causa } \\
\text { grave de accidentes de } \\
\text { tráfico }\end{array}$ & 3 \\
\hline $\begin{array}{l}\text { Ingravallo } F . \\
2008 \\
(19)\end{array}$ & $\begin{array}{l}\text { Revisión de } \\
\text { casos }\end{array}$ & $\begin{array}{l}\text { Narcolepsia y aptitud } \\
\text { para conducción }\end{array}$ & 15 & $\begin{array}{l}\text { La narcolepsia incapacita } \\
\text { gravemente }\end{array}$ & 3 \\
\hline
\end{tabular}

Del estudio de revisión de casos de Murray $\mathrm{TJ}^{18}$ se obtienen los siguiente resultados: Se estima que la incidencia de la narcolepsia es de un $0.3 \%$, que afecta a ambos sexos por igual y que un 10\% - 30\% tienen antecedentes familiares (herencia autosómica dominante). La relación de narcolepsia - accidente de tráfico queda patente en esta revisión al extraer de un estudio (Bartels Ec, kushachioglu 0: Narcolepsy: a possible cause of automobile accidents.Lahey Clin Found Bull 14: 21, 1965) que de 105 casos de pacientes con narcolepsia que conducían el $77 \%$ informó somnolencia durante la conducción en comparación con el $14 \%$ de controles, que el $40 \%$ de los casos se habían dormido realmente al volante frente al $7 \%$ de los controles y que el 16\% habían tenido uno o más accidentes durante la conciliación del sueño frente al $0.9 \%$ de los controles.

En el estudio realizado en Italia ${ }^{19}$ a 15 pacientes narcolépticos con diferentes grados de severidad a los que siguieron al menos 2 veces al año, se valoró la capacidad de conducción por cuatro Comisiones médicas en sesiones simuladas. Se concluye que la narcolepsia limita en gran medida el desempeño de la conducción, pero no hay criterios estándar para evaluar la discapacidad. Se obtuvieron los siguientes resultados: porcentaje de discapacidad ( $\mathrm{p}<0,001)$, la severidad de la discapacidad $(\mathrm{P}=0,0007)$ y la necesidad de informar a la autoridad del permiso de conducción $(P=0,032)$. El mayor sesgo está en la variabilidad interobservador. La revisión en la renovación de la licencia osciló entre el $73 \%$ al $100 \%$.

Según estos resultados las personas con narcolepsia tienen mayor probabilidad de tener accidentes de tráfico tal como dice el RD 818/2009.

\section{Trastorno del desarrollo intelectual}

Es una afección diagnosticada antes de los 18 años de edad que incluye un funcionamiento intelectual general por debajo del promedio y una carencia de las destrezas necesarias para la vida diaria.

Criterios de aptitud para obtener o prorrogar el permiso o licencia de conducción ordinarios: $\mathrm{El} \mathrm{RD}$ establece que no ha de existir retraso mental con un $\mathrm{CI}<70$. En los 
casos de retraso mental con CI entre 50 y 70 se podrá obtener o prorrogar si el interesado acompaña un dictamen favorable de un psiquiatra o psicólogo. (Grupos 1 y 2)

Si el dictamen del psiquiatra o psicólogo es favorable a la obtención de prórroga se podrán establecer condiciones restrictivas según criterio facultativo, para el grupo 1. Grupo 2 no se permiten.

\section{Trastornos del estado de ánimo}

Según el Diagnostic and Statistical Manual of Mental Disorders (DSM IV) los trastornos del estado del ánimo se definen como episodios afectivos, de carácter depresivo (estado de ánimo deprimido o pérdida del interés o sensación de placer), o maníaco, (estado de ánimo anormal y persistentemente elevado, expansivo o irritable.

Criterios de aptitud para obtener o prorrogar el permiso o licencia de conducción ordinarios: El RD establece para los carnés del Grupo 1 y 2 que no deben existir trastornos graves del estado del ánimo que conlleven alta probabilidad de conductas de riesgo para la propia vida o la de los demás.

Si existen adaptaciones, restricciones y otras limitaciones en personas, el RD establece para el Grupo 1 y 2 que, cuando, excepcionalmente, exista dictamen de un psiquiatra o psicólogo favorable a la obtención o prórroga, se podrá reducir el periodo de vigencia del permiso o licencia según criterio facultativo.

Tabla 8. Publicaciones analizadas sobre trastornos del estado del ánimo.

\begin{tabular}{|c|c|c|c|c|c|}
\hline $\begin{array}{l}\text { Primer autor/ } \\
\text { año/ref }\end{array}$ & $\begin{array}{l}\text { Tipo de } \\
\text { diseño }\end{array}$ & Variable resultado & $\begin{array}{l}\mathbf{N}^{\circ} \text { de } \\
\text { casos }\end{array}$ & Resultados & $\begin{array}{l}\text { Nivel de } \\
\text { evidencia }\end{array}$ \\
\hline $\begin{array}{l}\text { Las Cuevas C. } \\
2009(20)\end{array}$ & Transversal & $\begin{array}{l}\text { Trastornos mentales } \\
\text { yAptitud psicomotriz }\end{array}$ & 120 & $\begin{array}{l}\text { El } 80 \% \text { no superan el } \\
\text { test de conducción.Es } \\
\text { necesaria la aplicación } \\
\text { completa del test LNDITEL. }\end{array}$ & 3 \\
\hline $\begin{array}{l}\text { Hilton MF } \\
2009(21)\end{array}$ & Transversal & $\begin{array}{l}\text { Depresión, Ansiedad, } \\
\text { Estres y aumento de } \\
\text { acidentes viales en } \\
\text { conductor profesional. }\end{array}$ & 1324 & $\begin{array}{l}\text { Relación depresión y } \\
\text { accidentes ( }<<0,05) \text {. } \\
\text { Relación depresión } \\
\text { severa y muy severa y } \\
\text { accidentes (OR } 4.5 \text { y } 5 \\
\text { respectivamente) }\end{array}$ & 3 \\
\hline
\end{tabular}

En las dos publicaciones encontradas se utilizan estudios transversales, usando como herramientas de recogida de datos el test psicotécnico LNDITEL y el cuestionario $\mathrm{HPQ}^{\mathrm{iii}}$, y poder valorar la aptitud en la conducción y los riesgos de accidentes de tráfico en determinadas enfermedades mentales.

Las Cuevas ${ }^{20}$ observó en un estudio realizado con pacientes psiquiátricos con trastornos del estado del ánimo, esquizofrenias, estados neuróticos, trastornos de la personalidad y consumo de sustancias psicotropas, que únicamente el $20 \%$ de la población estudiada superaba las cuatro pruebas del test psicotécnico que son imprescindibles para obtener la aptitud. El 60\% no pasó la prueba de atención concentrada y resistencia a la monotonía, el 46\% fracasó en la prueba de reacciones múltiples (estímulos visuales) y el $40 \%$ no superó la prueba de coordinación bimanual. Un dato a tener en cuenta es que de los 120 pacientes que entraron en la muestra, $10(8,4 \%)$ eran conductores profesionales activos, de los cuales $8(80 \%)$ no superaron el test. Aunque el diseño del estudio no permite discriminar si son los fármacos utilizados, las enfermedades mentales y el tipo de enfermedad los que alteran las pruebas psicotécnicas, si se puede concluir que hay un funcionamiento psicomotor alterado que puede afectar a la conducción.

\footnotetext{
iii World Health Organisation Health and Performance at Work Questionaire.
} 
Por el contrario, en un estudio transversal realizado en Australia (Hilton y col) ${ }^{21}$ donde se aplica en una muestra de 1324 conductores activos de camiones un cuestionario que mide el impacto que provoca la depresión, la ansiedad y el estrés en el absentismo laboral, el desarrollo de su trabajo y en los accidentes de circulación en carretera, si se puede observar la forma en que estos trastornos mentales afectan a la seguridad vial. Centrándonos en el objetivo de esta revisión, se observa que en los resultados hay un 13,3\% de conductores que presentan síntomas con algún grado de depresión, un 7,9\% de ansiedad y un $7,5 \%$ de estrés. Viendo ya la relación entre las enfermedades mentales y los accidentes de circulación en los últimos 28 días, el análisis de regresión logística muestra que no hay grado de significancia para la ansiedad y el estrés, sin embargo, si la hay para la depresión $(P<0.05)$. La severa o muy severa depresión tiene un efecto muy alto en estar envuelto en un accidente o cerca de estarlo, con unos OR de 4.5 y 5 respectivamente. En las depresiones leves y moderadas el OR es de 2.04 y 1-93 respectivamente.

Los predictores de accidentes o cerca de serlos para esta enfermedad fueron el número de hijos, que reduce el riesgo de accidente ( $>4$ hijos $\mathrm{OR}=0.31)$, el ser conductor temporal, que lo aumenta $(\mathrm{OR}=3.1)$ y el número de enfermedades crónicas acompañantes, que igualmente lo aumenta $(\mathrm{OR}=$ de 3.3 a 3.6 para 4 o 5 enfermedades respectivamente).

Al igual que en el estudio de Las Cuevas ${ }^{20}$, se comprueba que son conductores en activo y que a pesar de tener enfermedades o síntomas que limitan o impiden la conducción siguen circulando sin ningún tipo de restricción o limitación.

El Reglamento General de Conductores recoge que no deben existir trastornos graves del estado de ánimo para la conducción, lo que el estudio de Hilton y col. ${ }^{21}$ en conductores profesionales apoya al demostrarse el alto riesgo de accidentes de tráfico al conducir en estas circunstancias. Si bien, queda a criterio de los especialistas valorar la aptitud a seguir cuando nos encontramos con estados leves o moderados de afectación.

\section{DISCUSIÓN}

Como se viene exponiendo, algunas patologías mentales merman la aptitud para conducir, por tanto, tendrán que tenerse en cuenta en la concesión de la licencia de conducción, al igual que en los exámenes de salud de los conductores profesionales realizados por el médico del trabajo. Para ello se valorarán las aptitudes psicofísicas en los centros acreditados (centros de reconocimientos psico-técnicos y servicios de prevención respectivamente) y, en el caso concreto de hallar patología mental, se necesitará el informe del especialista pertinente (psiquiatra, psicólogo y/o neurólogo) que determine la magnitud del trastorno mental y el grado de afectación sobre la persona y sus posibles consecuencias sobre la seguridad vial, daños a terceros, etc.

Algunos estudios encontrados inciden en el importante papel del especialista (psiquiatra, psicólogo y/o neurólogo) en la emisión del informe de aptitud para la conducción en personas con trastorno mental. El actual Reglamento General de Conductores en determinados trastornos mentales deja a criterio del neurólogo o psiquiatra la restricción para conducir sin determinar el periodo de tiempo, tanto para conductores ordinarios como para profesionales. No se han encontrado evidencias sobre los criterios que estos profesionales siguen en España a la hora de emitir dichos informes. Un estudio realizado en Inglaterra ${ }^{5}$ habla de los escasos recursos y conocimientos de los psiquiatras para determinar la aptitud en la conducción bajo estas circunstancias de salud. Según este estudio, estos profesionales desconocen en su mayoría las guías utilizadas por la Agencia Estatal de Conducción de Vehículos que unifican criterios sobre las aptitudes y acciones preventivas a desarrollar en el caso de conductores con trastornos mentales, por tanto, estos pacientes no son informados sobre los riesgos que conlleva conducir bajo sus condiciones psíquicas. En otro estudio realizado en Canadá ${ }^{22}$ se analiza la competencia de los neurólogos en la emisión de la aptitud para conducir de pacientes 
con demencia, obteniéndose que el $74 \%$ acertó en la no aptitud de estos pacientes para la conducción, por lo que se demuestra la falta de unificación de criterios y la escasa formación de los profesionales en esta materia.

En relación con la idea anterior nos planteamos la problemática expuesta en el artículo italiano sobre la aptitud en narcolepsia ${ }^{19}$, cuya idea podemos extrapolar al resto de patologías mentales. Nos encontramos ante una falta de unificación de criterios a la hora de, que valores medir y como interpretar los mismos. La no normalización de los criterios necesarios en los test psicológicos da lugar a que los resultados realizados por distinto médico no sean comparables, debido a la gran subjetividad en la percepción e interpretación de los datos.

Según resultados obtenidos, a esta problemática se suma que hay un porcentaje de conductores con enfermedad mental que continúan conduciendo, bien porque no han sido suficientemente bien valorados en los test psicotécnicos (durante la obtención del carné o en su renovación) o por patología sobrevenida durante el período de vigencia del carné hasta la próxima revisión. Es responsabilidad por parte de los conductores dejar de conducir y declarar ante las autoridades competentes cualquier trastorno psíquico que pueda afectar a la conducción. La omisión de este deber puede tener consecuencias graves que pueden no tener cobertura por el seguro obligatorio del vehículo. Diversos autores $^{5,20}$ advierten que muchos pacientes con trastornos mentales no declaran su enfermedad o tratamiento psiquiátrico y continúan conduciendo. Según La Cuevas, "solamente el 6,6\% de los conductores con procesos patológicos consideran que su aptitud para conducir está deteriorada, y de éstos, solo el 3,1\% han dejado de hacerlo".

No se han obtenido resultados de búsqueda sobre la capacidad del médico del trabajo a la hora de detectar estos trastornos en los exámenes de salud. Sin embargo, éste desempeña un papel primordial a la hora de identificar el riesgo que implica el ejercicio de la conducción en aquellos puestos de trabajo que lo requieren. A pesar de que existen recomendaciones de cómo manejar este problema en las consultas de atención primaria (mediante una anamnesis y exploración dirigidas, uso de escalas de valoración cognitiva, test neuro-psicológicos, etc) ${ }^{23,25,26,27}$ en la actualidad no hay constancia de que se estén aplicando por el médico del trabajo en los servicios de prevención, por lo que muchos trabajadores con estas patologías son considerados aptos para sus puestos de trabajo cuando no deberían serlo bajo esas circunstancias.

La Agencia Española de Protección de Datos ampara el artículo 63 del RD 339/1990 de 2 marzo, por el que en caso de que un trastorno mental sea detectado por el médico del trabajo en un examen de salud, éste podrá alertar a la Jefatura Provincial de Tráfico sobre la supuesta carencia de las aptitudes psicofísicas exigidas para conducir (acreditada por el especialista) y que, por tanto, entrañe un grave peligro para la seguridad vial. Será la Autoridad Administrativa competente la que determine la suspensión cautelar del permiso de conducción ${ }^{24}$.

\section{CONCLUSIONES}

- La literatura revisada concuerda con lo establecido por el RD 818/2009 en cuanto a los criterios de aptitud de conductores con enfermedades mentales; aún así existen aspectos que en ocasiones podrían dificultar su cumplimiento.

- El Reglamento General de Conductores dispone que las limitaciones y/o restricciones para conducir sean establecidas y acreditadas por un especialista (psiquiatra, neurólogo y/o psicólogo). En comparación con otros países no se dispone de datos que indiquen que en España haya criterios comunes de aplicación en esta materia por los especialistas competentes para ello.

- Existen conductores con diferentes grados de patología mental que continúan conduciendo a pesar de la merma que suponen estas enfermedades en su aptitud para conducir poniendo en peligro su integridad personal y la de terceros. 
- No se encuentra suficiente evidencia sobre si los test psico-técnicos, utilizados en las pruebas de aptitud psicofísicas en los centros homologados para la obtención o renovación de la licencia de conducción, son suficientemente sensibles y específicos para la detección de trastornos mentales.

- No existe obligación por parte del conductor con patología mental de declarar su enfermedad a la hora de obtener o renovar el carné de conducir, aunque sí hay una responsabilidad moral para ello, dados los riegos que conlleva no hacerlo.

- Los conductores profesionales con patología mental requieren una vigilancia de la salud más estrecha donde es necesaria la colaboración multidisciplinar entre médico del trabajo, atención primaria y especialistas a la hora de poder detectar precozmente y controlar estos procesos.

- Queda a criterio subjetivo del especialista competente para ello (médico del trabajo, neurólogo, psiquiatra, psicólogo) la valoración de la aptitud en conductores con patología mental.

- No hay evidencia de que se utilicen tests o pruebas psicofísicas en los Servicios de Prevención de Riesgos Laborales para la valoración de la aptitud de conductores profesionales con trastornos mentales, quedando la detección de dichos problemas confinada a la mera declaración de su patología por parte del trabajador (que puede o no aportar informes médicos) o a la expresión evidente de clínica de patología mental durante el examen de salud.

\section{REFERENCIAS BIBLIOGRÁFICAS}

1. Álvarez González FJ, González Luque JC, Lascorz Ayat T, Mirabet Lis, E, Ozcoidi Val M, Pérez Torralba F. Guía del Consejo Sanitario en Seguridad Vial Laboral. Observatorio Nacional de Seguridad Vial. Dirección General de Tráfico. Ministerio del Interior. Madrid. 2010.

2. Real Decreto 818/2009 del 8 de mayo, por el que se aprueba el Reglamento General de Conductores. Boletín oficial del Estado Núm. 138 (Lunes 8 de junio de 2009) Sec. I. Pág. 48068 a 48182.

3. Civera Mollá C, Pastor Soriano JC, Alonso Plá F. Un siglo de selección de conductores en España. Univ. Psychol. Bogotá (Colombia) 2002; 1 (1): 19-30.

4. Badanes Guía D, Casas Hernanz L, Cejudo Bolivar JC, Aguilar Barberá M. Valoración de la capacidad de conducción de vehículos en pacientes con diagnóstico de deterioro cognitivo leve y demencia. Neurología 2008; 23(9):574-582.

5. Breen DA, Breen DP, Moore JW, Breen PA, O`Neill D. Driving and Demencia. BMJ 2007; 334:1365-9.

6. Nabi H, Consoli SM, Chiron M, Lafont S, Chastang JF, Zins M, Lagarde E. Aggressive/hostile personality traits and injury accidents: an eight-year prospective study of a large cohort of French employees -- the GAZEL cohort. Psychol Med. 2006 Mar; 36(3):365-73.

7. Dumais A, Lesage AD, Boyer R, Lalovic A, Chawky N, Ménard-Buteau C, Kim C, Turecki G. Psychiatric risk factors for motor vehicle fatalities in young men. Can J Psychiatry. 2005 Nov; 50(13):838-44.

8. Thompson AL, Molina BS, Pelham W Jr, Gnagy EM. Risky driving in adolescents and young adults with childhood ADHD. J Pediatr Psychol. 2007 Aug; 32(7):745-59.

9. Reimer B, D'Ambrosio LA, Coughlin JF, Fried R, Biederman J. Task-induced fatigue and collisions in adult drivers with attention deficit hyperactivity disorder. Traffic Inj Prev. 2007 Sep; 8(3):290-9.

10. Weafer J, Camarillo D, Fillmore MT, Milich R, Marczinski CA. Simulated driving performance of adults with ADHD: comparisons with alcohol intoxication. Exp Clin Psychopharmacol. 2008 Jun; 16(3):251-63.

11. Inglott Domínguez R, Touriño González R, Baena Ruiz E, Fernández Fernández J. Intervención familiar en la esquizofrenia: su diseminación en un Área de Salud. Asoc. Esp. Neuropsiq. 2004; 92: 2442-2455.

12. Gómez Esteban, R.; Martín Vázquez, Mª J.; González López, A.; Flores Álvarez, M.; Bote Bonaechea, B.; Güerre Lobera, $\mathbf{M}^{\mathrm{a}} \mathrm{J}$. Reflexiones acerca de un grupo terapéutico con pacientes esquizofrénicos. Revista de la Sociedad Española de Neuropsiquiatría. 2003; 88: 2628-2643.

13. Odegaard, O.The Incidence Of Psychoses In Various Occupations. International Journal of Social Psychiatrists (OSH Update) año 1956, 2(2): 85 - 104.

14. Laux G. Psychiatric disorders and fitness to drive an automobile. Der Nervenarzt. 2002 Mar;73(3):231-8. 
15. De Wolf. M.M.Rijgeschiktheid bij psychiatrische aandoeningen. Literetuuroverzicht en consequenties voor de praktijk. Tijdschrift voor psychiatrie. 2010; 52: 555-564.

16. Gómez-Talegón, M. T.; Fierro Lorenzo, I.; África Vicondoa; Ozcoidi, M.; Álvarez González, F.J. Aptitud para conducir de los pacientes con trastornos mentales: su evaluación en los centros de reconocimiento de conductores. Psiquiatría biológica: Publicación oficial de la Sociedad Española de Psiquiatría Biológica. 2008 May;15(3):63-72.

17. Findley L, Unverzagt M, Guchu R, Fabrizio M, Buckner J, Suratt P. Vigilance and Automobile Accidents in Patients With Sleep Apnea or Narcolepsy. Chest. 1995; 108 (3): 619-624.

18. Murray TJ, Foley A. Narcolepsy. CMA Journal. 1974; (110): 63-66.

19. Ingravallo, F. Vignatelli, L. Brini M. Brugaletta C. Franceschini, C. Lugaresi, F. et al. Medico-legal assessment of disability in narcolepsy: an interobserver reliability study; European Sleep Research Society; 2008 July; (17): 111-119.

20. Las Cuevas Castresana C de, Sanz Alvarez EJ. Enfermedad mental y seguridad vial. Actas Esp de Psiquiatr 2009; 37(2):75-81.

21. Hilton MF, Staddon Z, Sheridan J, Whiteford HA. The impact of mental health symptoms on heavy goods vehicle drivers' performance. Accid. Anal. Prev. 2009; 41(3):453-461.

22. Mark J, Rapoport M, Herman N, Frank J, Molnar F, Man-Son-Hing M et al. Sharing the responsibility for assessing the risk of the driver with dementia. CMAJ. 2007; 177(6):599-601.

23. Álvarez-Blázquez Fernández F, Álvarez Gómez S, Andrés Manzano B, Arancon Vigueras A, Arrollo Molina P, Artazcoz Ardanaz JF y col. "Guía de Valoración de Incapacidad Laboral para Médicos de Atención Primaria”. Escuela Nacional de Medicina del Trabajo (ENMT). Instituto de Salud Carlos III. Ministerio de Ciencia e Innovación. Madrid. 2009. Álvarez-Blázquez Fernández F, Director. Jardon Dato E, Carbajo Sotillo MD, Terradillos García MJ, Valero Muñoz MR, Robledo Muga F, Maqueda Blasco J, Cortés Barragán R, Veiga de Cabo J, coordinadores.

24. Real Decreto legislativo 339/1990, de 2 de marzo, por el que se aprueba el texto articulado de la Ley sobre Tráfico, Circulación de Vehículos a Motor y Seguridad Vial. Boletín Oficial del Estado Núm. 63 de 14/3/1990, Pág. 7259 a 7270.

25. Silva MT, Laks J, Engelhardt E. Neuropsychological tests and driving in dementia: a review of the recent literatura. Rev Assoc Med Bras. 2009; 55(4): 484-8.

26. Herrmann N, Rapoport MJ, Sambrook R, Hébert R, McCracken P, Robillard A. Predictors of driving cessation in mild-to-moderate dementia. CMAJ. 2006; 175(6): 591-95.

27. Dawson JD, Anderson SW, Uc EY, Dastrup E, Rizzo M. Predictors of driving safety in early Alzheimer disease. Neurology 72. 2009; 72(6): 521-27. 


\section{ANEXO I. CONCEPTO DE ACCIDENTE DE TRABAJO. REAL DECRETO 1/1994 (ART. 115) DE LA LEY GENERAL DE LA SEGURIDAD SOCIAL.}

1. Se entiende por accidente de trabajo toda lesión corporal que el trabajador sufra con ocasión o por consecuencia del trabajo que ejecute por cuenta ajena.

2. Tendrán la consideración de accidentes de trabajo:

a. Los que sufra el trabajador al ir o al volver del lugar de trabajo.

b. Los que sufra el trabajador con ocasión o como consecuencia del desempeño de cargos electivos de carácter sindical, así como los ocurridos al ir o al volver del lugar en que se ejerciten las funciones propias de dichos cargos.

c. Los ocurridos con ocasión o por consecuencia de las tareas que, aun siendo distintas a las de su categoría profesional, ejecute el trabajador en cumplimiento de las órdenes del empresario o espontáneamente en interés del buen funcionamiento de la empresa.

d. Los acaecidos en actos de salvamento y en otros de naturaleza análoga, cuando unos y otros tengan conexión con el trabajo.

e. Las enfermedades, no incluidas en la clasificación como profesionales, que contraiga el trabajador con motivo de la realización de su trabajo, siempre que se pruebe que la enfermedad tuvo por causa exclusiva la ejecución del mismo.

f. Las enfermedades o defectos, padecidos con anterioridad por el trabajador, que se agraven como consecuencia de la lesión constitutiva del accidente.

g. Las consecuencias del accidente que resulten modificadas en su naturaleza, duración, gravedad o terminación, por enfermedades intercurrentes, que constituyan complicaciones derivadas del proceso patológico determinado por el accidente mismo o tengan su origen en afecciones adquiridas en el nuevo medio en que se haya situado el paciente para su curación.

3. Se presumirá, salvo prueba en contrario, que son constitutivas de accidente de trabajo las lesiones que sufra el trabajador durante el tiempo y en el lugar del trabajo.

4. No obstante lo establecido en los apartados anteriores, no tendrán la consideración de accidente de trabajo:

a. Los que sean debidos a fuerza mayor extraña al trabajo, entendiéndose por ésta la que sea de tal naturaleza que ninguna relación guarde con el trabajo que se ejecutaba al ocurrir el accidente.

En ningún caso se considerará fuerza mayor extraña al trabajo la insolación, el rayo y otros fenómenos análogos de la naturaleza.

b. Los que sean debidos a dolo o a imprudencia temeraria del trabajador accidentado.

5. No impedirán la calificación de un accidente como de trabajo:

a. La imprudencia profesional que es consecuencia del ejercicio habitual de un trabajo y se deriva de la confianza que éste inspira.

b. La concurrencia de culpabilidad civil o criminal del empresario, de un compañero de trabajo del accidentado o de un tercero, salvo que no guarde relación alguna con el trabajo. 


\section{ANEXO II. NIVEL DE EVIDENCIA CIENTÍFICA: SCOTTISH INTERCOLLEGIATE GUIDELINES NETWORK (SIGN)}

1++ Meta-análisis de gran calidad, revisiones sistemáticas de ensayos clínicos aleatorizados aleatorizados o ensayos clínicos aleatorizados con muy bajo riesgo de sesgos.

1+ Metaanálisis de gran calidad, revisiones sistemáticas de ensayos clínicos aleatorizados o ensayos clínicos aleatorizados con bajo riesgo de sesgos.

1- Metaanálisis de gran calidad, revisiones sistemáticas de ensayos clínicos aleatorizados o ensayos clínicos aleatorizados con alto riesgo de sesgos.

2++ Revisiones sistemáticas de alta calidad de estudios de cohortes o de casoscontroles, o estudios de cohortes o de casos-controles de alta calidad, con muy bajo riesgo de confusión, sesgos o azar y una alta probabilidad de que la relación sea causal.

2+ Estudios de cohortes o de casos-controles bien realizados, con bajo riesgo de confusión, sesgos o azar y una moderada probabilidad de que la relación sea causal

2- $\quad$ Estudios de cohortes o de casos y controles con alto riesgo de sesgo

3 Estudios no analíticos, como informe de casos y series de casos

$4 \quad$ Opinión de expertos 